\title{
Article \\ In silico Prediction and Cytotoxicity Evaluation of siRNAs Targeting Conserved Regions of MERS-CoV in Cell Culture
}

\author{
Sayed Sartaj Sohrab ${ }^{1,2, *}$, Sherif Aly El-Kafrawy ${ }^{1,2}$, Zeenat Mirza ${ }^{2,3}$, Esam Ibraheem Azhar ${ }^{1,2}$ \\ 1 Special Infectious Agents Unit, King Fahd Medical Research Center, King Abdulaziz University, \\ Jeddah, Saudi Arabia; \\ SSS: ssohrab@kau.edu.sa, SAE: saelkfrawy@kau.edu.sa, EIA: eazhar@kau.edu.sa \\ 2 Department of Medical Laboratory Technology, Faculty of Applied Medical Sciences, King \\ Abdulaziz University, Jeddah, Saudi Arabia. \\ SSS: ssohrab@kau.edu.sa, SAE: saelkfrawy@kau.edu.sa, ZM: ZM: zmirza1@kau.edu.sa, EIA: \\ eazhar@kau.edu.sa \\ 3. King Fahd Medical Research Center, King Abdulaziz University, Jeddah, Saudi Arabia. ZM: \\ zmirza1@kau.edu.sa
}

* Correspondence: Dr. Sayed Sartaj Sohrab

ssohrab@kau.edu.sa, sayedsartaj@gmail.com

Tel.: (+966554627872)

\begin{abstract}
The Middle East Respiratory Syndrome Coronavirus (MERS-CoV) was isolated in 2012 and is well known to cause the respiratory syndrome. The orflab gene is known to mediate MERS-CoV replication. In this study, we have discussed the in silico prediction of potential siRNAs targeting MERS-CoV-orflab gene for antiviral therapeutics. To identify the potential siRNAs, various factors were considered. We have excluded the siRNAs with off-target effects and potential binding with human mRNAs. By using available softwares, total twenty-one functional, off-target reduced potential siRNA were selected from four hundred and sixty-two siRNAs based on greater potency and specificity. We have tested only seven siRNAs initially to evaluate their performance by reverse transfection approach by lipofectamine mediated delivery in Vero cells. The evaluation results showed no cytotoxicity at various concentrations of siRNAs used. The results obtained in this study provided preliminary information about the cytotoxicity which will help us to further evaluate siRNAs in other cell cultures to find out the replication inhibition efficiency of MERS-CoV. Finally, it is concluded that the in silico prediction and designing resulted in filtration and selection of potential siRNAs with high accuracy, efficiency, and strength which can be further utilized for the development of oligonucleotide-based therapeutics.
\end{abstract}

Keywords: MERS-CoV, siRNAs, in silico design, Vero cells.

\section{Introduction}

MERS-CoV presents a major health concern for both human and animal. The first case was identified in June 2012 from Jeddah, Saudi Arabia [1]. Currently, a total of 2,279 confirmed MERS-CoV cases with 806 related deaths have been reported and spread in 27 countries (WHO-last accessed on February 24, 2019). The virus is mainly transmitted to human in family clusters, healthcare workers, through contact with camels as well as community settings [2-7]. MERS-CoV causes lower respiratory infections with fever and cough followed by shortness of breath and organ failure in cases with comorbidities [8]. Coronaviruses genome varies from 25.0 to $32.0 \mathrm{~kb}$ and have high sequence variation which favors the possible recombination and emergence of new virus strains with novel characters in the extended hosts [9].

The RNA interference (RNAi) is an important biological process found in many eukaryotes in which RNA molecules inhibit gene expression. Two molecules (miRNA and siRNAs) are known as central to RNAi. The main function of siRNA is to downregulate and silence the specific gene by degrading the mRNA after transcription [10]. The regulatory role of RNAi in gene expression has been shown in many in vitro and in vivo studies [11]. Short interfering RNAs (siRNA) are short sequences of RNA that varies from 21 to 23 base pairs with 5' phosphate group and a 3' hydroxyl group. They function by binding to a specific protein known as RNA induced silencing complex (RISC), RISC then forms a new complex with specific RNA sequences and degrades the RNA resulting into silencing of mRNA expression [12]. As all siRNAs are not equally potent, simple rules have been suggested for the computational selection of efficient siRNAs. The designing softwares combining the structural features of the targeted RNAs as well as the sequence features of the siRNAs are the good choice.

Currently, the siRNA approach has been implemented to inhibit virus replication in cell culture against many viruses like HIV [13], Flock house virus (FHV) [14], Rous sarcoma virus [15], Dengue virus [16], 
Hepatitis C virus (HCV) [17], Influenza virus [18,19], Hepatitis B virus (HBV) [20,21], Human Papillomavirus (HPV) [22], SARS coronavirus [23] etc. The in silico designing of siRNA helps in predicting potential siRNAs candidates with high target specificity and reduced off-target effects. Before designing of potential siRNAs, various issues should be considered like conserved genome sequences, off-target effects, siRNA folding, thermodynamics, target accessibility, stability and immuno-stimulation of siRNAs. Many investigations have provided the basic rules and guidelines for siRNAs designing [24-26].

The in vitro efficacy of siRNA was reported for the inhibition of other coronaviruses. Cytopathic effect was specifically inhibited by siRNA targeting viral RNA polymerases of SARS-CoV in Vero cells [27]. The titer and levels of viral proteins were reduced to indicate blocking of viral replication. S gene of SARS-CoV was selectively silenced by DNA vector-driven siRNA in SARS-infected 293T cells. Another study showed that SARS-CoV infection and replication in fetal rhesus kidney cells (FRhK-4) was inhibited by 3 siRNA duplexes targeting viral RNA polymerases, and one targeting the $\mathrm{S}$ gene [28]. The siRNA duplexes had a prolonged prophylactic effect, with $\leq 90 \%$ inhibition of transcription, lasting for $\geq 72 \mathrm{~h}$. Combinations of siRNA duplexes against multiple targets in the viral genome showed $\leq 80 \%$ inhibition. Therapeutic siRNAs and miRNAs are found to be the most promising biopharmaceuticals in commercial space as oligonucleotide-based next-generation medicines. Currently, miRNA- and siRNA-based candidate drugs are being evaluated in $\sim 20$ clinical trials [29].

For MERS-CoV, two studies have reported in silico design of siRNA and miRNA against orflab replicase polyprotein using computational methods for possible use as antiviral therapeutics against MERSCoV [30,31]. Recently, we have also reviewed the design and delivery of potential siRNAs for MERS-CoV [26]. In the present study, we report the in silico design, synthesis and cytotoxic effect of seven siRNAs targeting the orflab region of the MERS-CoV viral genome.

\section{Materials and Methods}

\subsection{Sequence isolation and analysis}

Total seventeen Orf $1 \mathrm{ab}$ gene sequences of MERS-CoV isolated from human and camels were downloaded from GenBank. Sequences were multiple aligned using BioEdit sequence alignment tool and ClustalW software, the accession numbers and their sequence identity matrix are presented in Table 1.

\subsection{In silico prediction and Scoring of siRNAs}

The MERS-CoV genome sequences were retrieved from NCBI database submitted from various countries and orflab gene was extracted for multiple sequence alignment and siRNA prediction. The overall flow for prediction and selection of potential siRNAs has been presented in Figure 1. The characteristics and thermodynamic properties of predicted siRNAs are presented in Table 2.

\subsection{Screening of Off-Targets}

We used two different phases of selection to avoid any off-target binding of the designed siRNAs. We performed BLAST and Smith-Waterman algorithms as implemented in ParAlign to find out the near complimentary and similarity match with human mRNA sequences in NCBI database and increase the validity percentage of the siRNAs and filtered out the siRNAs with reduced off-targets effect [32-34]. In the next phase, siRNAs were filtered through the exclusion of seed-region like human mRNA [35].

\subsection{Thermodynamics, Target Accessibility, and secondary structure prediction}

The thermodynamics and target accessibility were performed by using RNAxs tool [36,37] and secondary structure of siRNA was designed utilizing RNAfold server (http://rna.tbi.univie.ac.at). This program helps in the calculation of minimum free energy and partition function of RNAs by reading the RNA sequences.

\subsection{Final selection and chemical synthesis of siRNAs}

The siRNAs were finally selected based on the best parameters following the rule of Ui-Tei, Reynolds and Amarzguioui [24,38-40]. The predicted siRNAs against the targeted Orf 1ab gene of MERS-CoV were chemically synthesized by Integrated DNA Technologies (USA) (Table 2).

\section{Cytotoxicity evaluation of siRNAs in cell culture \\ 3.1 Cell Culture and siRNAs transfection}

The Vero cells (ATCCCCL-81) were grown and maintained in complete DMEM medium at $37^{\circ} \mathrm{C}$ and $5 \% \mathrm{CO}_{2}$ and used for siRNA transfection by reverse transfection. The Vero cells $\left(1 \times 10^{4}\right)$ were plated into $96-$ well plates (in triplicates) with 60-80\% confluency and transfected with siRNAs using Lipofectamine 2000 (Invitrogen, USA) as transfection reagent following the manufacturer's instructions. Briefly, the complex was 
prepared by diluting $50 \mu \mathrm{M}$ siRNAs stocks at various concentration $(0.01$ to $50 \mathrm{nM})$ in $100 \mu$ l Opti-MEM medium by adding Lipofectamine and incubated for 30 minutes at room temperature. The siRNA-lipid complex $(1 \mu \mathrm{l})$ was added to the Vero cells at various siRNA concentration $(0.01-50 \mathrm{nM})$ and mixed gently. Vero cells without siRNA, cells with Opti-MEM and cells with Lipofectamine were used as negative controls. The transfected cells were incubated for three days at $37^{\circ} \mathrm{C}$. After 72 hours post-transfection cytotoxicity assay was performed on the transfected cells.

\subsection{Cytotoxicity Assay}

The cytotoxicity of siRNA-Lipofectamine 2000 complex on Vero cells was evaluated by MTT [3-(4,5dimethylthiazol-2-yl)-2,5-diphenyltetrazolium bromide] assay. After 72 hours post-transfection, media containing transfection reagents were removed and $100 \mu \mathrm{l}$ of fresh media was added to the Vero cells. The MTT assay was performed by using Vybrant ${ }^{\mathrm{TM}}$ MTT Cell Proliferation Assay kit (Invitrogen) as per manufacturer's instructions. A total of $10 \mu \mathrm{l}$ MTT stock solution $(12 \mathrm{mM})$ was added and incubated at $37^{\circ} \mathrm{C}$ for four hours. The formazan crystals were dissolved in $100 \mu \mathrm{L}$ SDS-HCL solution by further incubation at $37^{\circ} \mathrm{C}$ for four hours. The samples were mixed thoroughly, and absorbance was measured at 570nm using SpectraMax i3x imaging cytometer. All the experiments were performed in triplicates and the mean value of OD was used for calculating cytotoxicity using the standard formula.

\section{Results}

\subsection{MERS-CoV genome analysis, in silico prediction, and selection of potential siRNAs}

After performing the whole genome sequence analysis of MERS-CoV, we selected the orflab gene as a target region for further sequence analysis. The multiple sequence alignment results showed high conservation among all the sequences analyzed. Multiple sequence alignment of the MERS-CoV strains showed that Orf 1ab gene to be highly conserved. In silico analysis and scoring of potential siRNAs targeting the targeted Orf $1 \mathrm{ab}$ gene of the MERS-CoV was performed using online software siDirect 2.0 [24,39,40]. Potential siRNAs with no off-target matches with any human mRNA sequences were filtered and selected. The outline for in silico prediction, filtration and final selection of potential siRNA with high scores without off-target effects has been given in figure 1. During in silico prediction, many siRNAs were found to fulfill the less favorable criteria targeting a region in the orflab genome of MERS-CoV. By using this strategy, we selected total twenty-one functional, off-target reduced potential siRNA from four hundred and sixty-two siRNAs based on their predicted high specificity and potency and the resulting candidates were further narrowed down to only seven siRNA as per the guidelines and rule of Ui-Tei, Reynolds and Amarzguioui $[24,39,40]$. The predicted siRNAs were expected to be highly specific and potent against MERS-CoV.

\subsection{Target accessibility and secondary structure prediction}

The thermodynamic properties and target accessibility were performed using RNAxs tool and results are presented in figure 2 , table 2 . The target accessibility analysis provided the binding position of each siRNAs at starting point along the Orflab gene of the viral genome such as siRNA-1:110, siRNA-2:32, siRNA-3:1184, siRNA-4:180, siRNA-5:1230, siRNA-6:291, siRNA-7:5167 of the viral genome. The secondary structure prediction was performed using RNAfold with only seven siRNAs sequences to screen initially about the performance of selected siRNAs in the cell culture and the structures are presented in figure 3 . Based on results obtained using online software the results of thermodynamic ensemble prediction, the minimum free energy was observed to be $-2508.09 \mathrm{kcal} / \mathrm{mol}$ and the ensemble diversity was 1611.05 for partial Orf $1 \mathrm{ab}$ genome of MERS-CoV.

\section{3 $\operatorname{siRNA}$ transfection and Cytotoxicity Assay}

The reverse transfection using Lipofectamine 2000 was performed to mediate the delivery of siRNAs to Vero cells. The cytotoxicity results are presented in figure 4 and table 3 . The cytotoxicity was evaluated for seven siRNAs to screen the performance of these siRNAs in Vero cells and cytotoxic effects of the selected siRNA were found to be concentration dependent. The CC50 was observed to be variable for each siRNAs: siRNA-1: 220.2, siRNA-2:408.3, siRNA-3:345.2, siRNA-4:322.9, siRNA-5:270.7, siRNA-6:491.6, siRNA7:187.3. None of the tested siRNAs showed cytotoxicity to Vero cells up to 50nm concentration. 


\section{MERS-CoV sequence from NCBI}

\section{Collection}

$\Downarrow$

Multiple sequence Alignment by

$\Downarrow$

Designing of Potential siRNAs

$\Downarrow$

Threshold score (70-90\% inhibition) for MER-CoV-orf 1ab

Off-target matching, Target accessibility and

\section{Threshold score}

$\Downarrow$
Alianment

Designing

Filtration

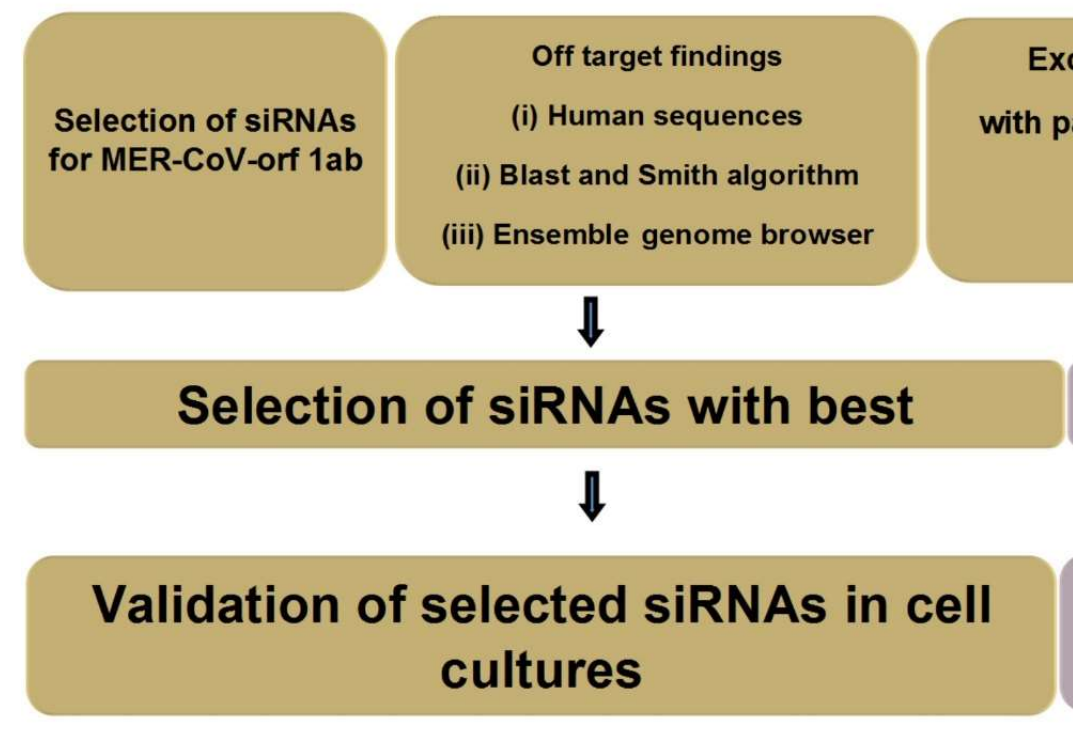

Final

\section{Validation}

Figure 1: Flow diagram of in silico prediction and design of potential siRNAs against MERS-CoV orflab. 
5 of 12


Figure 2: Target accessibility of potential siRNAs by RNAxs programme. 
6 of 12

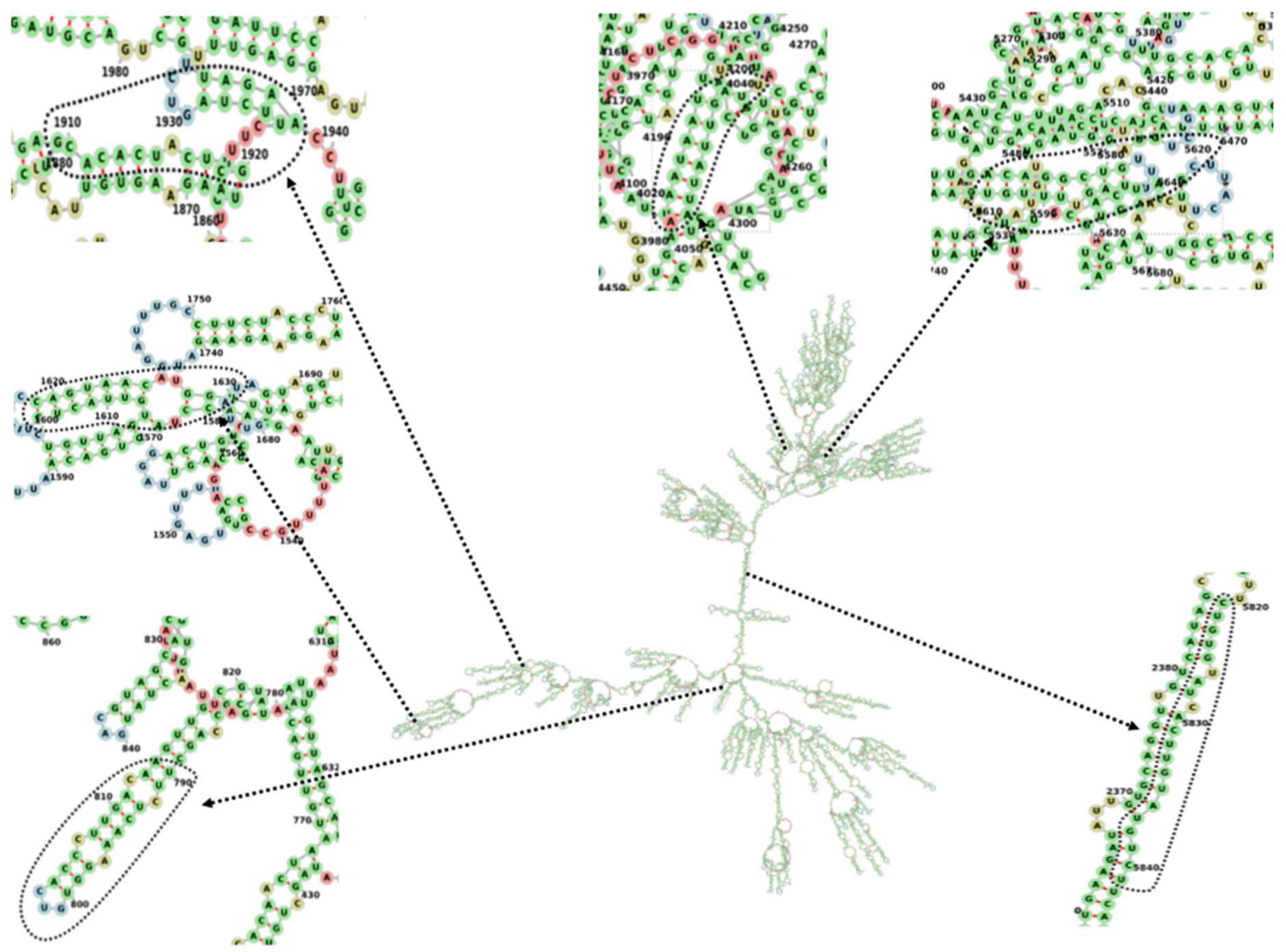

Figure 3: Secondary structure generated by RNAfold and binding position of potential siRNAs.

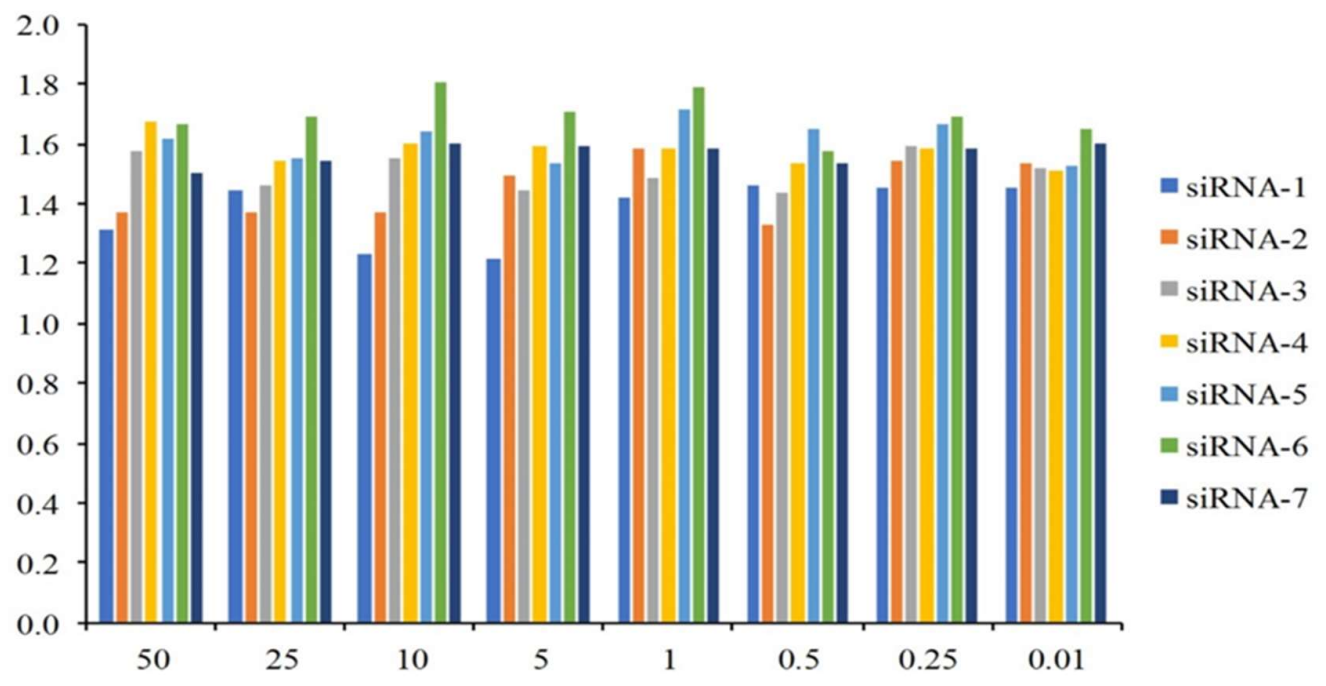

Figure 4: Cytotoxicity of different siRNAs at various concentrations (50-0.01Nm) 
Table 1. Sequence Identity Matrix of Selected MERS-CoV based on full genome.

\begin{tabular}{lllll}
\hline $\begin{array}{l}\text { Accession } \\
\text { numbers }\end{array}$ & Locations & Hosts & Year & \% Identity \\
\hline KF958702 & Jeddah & Human & 2014 & 99.0 \\
KU851859 & Jeddah & Human & 2015 & 99.6 \\
KF192507 & UAE & Human & 2013 & 99.8 \\
KT156561 & Oman & Human & 2013 & 99.7 \\
KT861628 & Jordan & Human & 2014 & 99.7 \\
KX034100 & Korea & Human & 2015 & 99.7 \\
KT036372 & Chia & Human & 2015 & 99.6 \\
KP223131 & Florida & Human & 2014 & 99.8 \\
NC019843 & Netherland & Human & 2012 & 99.6 \\
KF745068 & France & Human & 2013 & 99.7 \\
KT225476 & Thailand & Human & 2015 & 99.7 \\
KJ556336 & Jeddah & Human & 2013 & 92.3 \\
KF917527 & Jeddah & Camel & 2013 & 99.9 \\
KX108946 & UAE & Camel & 2015 & 99.6 \\
KJ650098 & Qatar & Camel & 2014 & 99.8 \\
KT368879 & Riyadh & Camel & 2015 & 99.7 \\
KJ477102 & Egypt & Camel & 2013 & 99.4 \\
\hline
\end{tabular}

Table 2. List of predicted potential siRNAs in MERS-CoV orflab gene (KF958702-Jeddah).

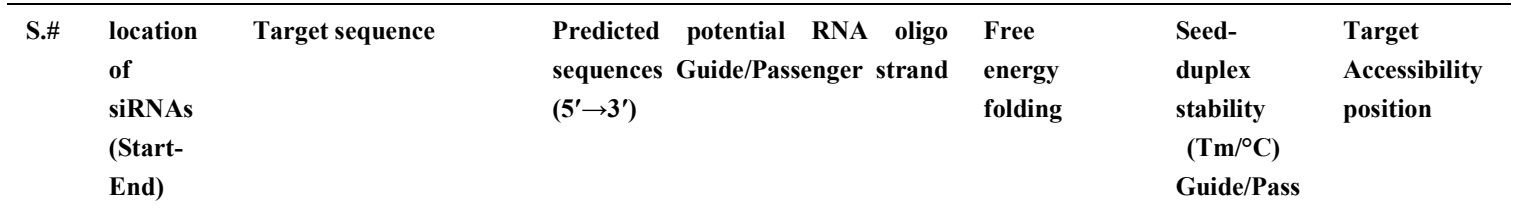

\begin{tabular}{|c|c|c|c|c|c|c|}
\hline 1 & $791-813$ & $\begin{array}{l}\text { AGCAATCTATTTTTA } \\
\text { CTATTAAT }\end{array}$ & $\begin{array}{l}\text { UAAUAGUAAAAAUAGAUUGCU } \\
\text { CAAUCUAUUUUUACUAUUAAU }\end{array}$ & 0.84 & $6.3 / 6.6$ & 110 \\
\hline 2 & $\begin{array}{l}1615- \\
1637\end{array}$ & $\begin{array}{l}\text { ATGGATAATGCTATT } \\
\text { AATGTTGG }\end{array}$ & $\begin{array}{l}\text { AACAUUAAUAGCAUUAUCCAU } \\
\text { GGAUAAUGCUAUUAAUGUUGG }\end{array}$ & 0.75 & $6.9 / 8.7$ & 32 \\
\hline 3 & $\begin{array}{l}1910- \\
1932\end{array}$ & $\begin{array}{l}\text { GCGACTTTATGTCTA } \\
\text { CAATTATT }\end{array}$ & $\begin{array}{l}\text { UAAUUGUAGACAUAAAGUCGC } \\
\text { GACUUUAUGUCUACAAUUAUU }\end{array}$ & 0.81 & $6.9 / 4.6$ & 1184 \\
\hline 4 & $\begin{array}{l}4018- \\
4040\end{array}$ & $\begin{array}{l}\text { GACACTTTAGATGA } \\
\text { TATCTTACA }\end{array}$ & $\begin{array}{l}\text { UAAGAUAUCAUCUAAAGUGUC } \\
\text { CACUUUAGAUGAUAUCUUACA }\end{array}$ & 0.70 & $6.6 / 9.8$ & 180 \\
\hline 5 & $\begin{array}{l}5597- \\
5619\end{array}$ & $\begin{array}{l}\text { ATGCTATTAGTTTGA } \\
\text { GTTTTAAT }\end{array}$ & $\begin{array}{l}\text { UAAAACUCAAACUAAUAGCAU } \\
\text { GCUAUUAGUUUGAGUUUUAAU }\end{array}$ & 0.78 & $13.3 / 2.8$ & 1230 \\
\hline 6 & $\begin{array}{l}5598- \\
5620\end{array}$ & $\begin{array}{l}\text { TGCTATTAGTTTGAG } \\
\text { TTTTAATA }\end{array}$ & $\begin{array}{l}\text { UUAAAACUCAAACUAAUAGCA } \\
\text { CUAUUAGUUUGAGUUUUAAUA }\end{array}$ & 0.81 & $4.9 / 6.3$ & 291 \\
\hline 7 & $\begin{array}{l}5819- \\
5841\end{array}$ & $\begin{array}{l}\text { GAGCTAGTTTGCGTC } \\
\text { AAATTTTT }\end{array}$ & $\begin{array}{l}\text { AAAUUUGACGCAAACUAGCUC } \\
\text { GCUAGUUUGCGUCAAAUUUUU }\end{array}$ & 0.70 & $7.4 / 9.8$ & 5167 \\
\hline
\end{tabular}


8 of 12

Table 3. Mean OD value and cytotoxicity of different siRNAs at various concentrations

\begin{tabular}{|c|c|c|c|c|c|c|c|}
\hline Concentrations (nM) & siRNAs-1 & siRNAs-2 & siRNAs-3 & siRNAs-4 & siRNAs-5 & siRNAs-6 & siRNAs-7 \\
\hline & & & & & & & 1.5 \\
\hline 50 & 1.3 & 1.4 & 1.6 & 1.7 & 1.6 & 1.7 & \\
\hline 25 & 1.4 & 1.4 & 1.5 & 1.5 & 1.6 & 1.7 & 1.5 \\
\hline 10 & 1.2 & 1.4 & 1.6 & 1.6 & 1.6 & 1.8 & 1.6 \\
\hline 5.0 & 1.2 & 1.5 & 1.4 & 1.6 & 1.5 & 1.7 & 1.6 \\
\hline 1.0 & 1.4 & 1.6 & 1.5 & 1.6 & 1.7 & 1.8 & 1.6 \\
\hline 0.5 & 1.5 & 1.3 & 1.4 & 1.5 & 1.6 & 1.6 & 1.5 \\
\hline 0.25 & 1.5 & 1.5 & 1.6 & 1.6 & 1.7 & 1.7 & 1.6 \\
\hline 0.01 & 1.5 & 1.5 & 1.5 & 1.5 & 1.5 & 1.5 & 1.6 \\
\hline CC 50 & & & 345.2 & 322.9 & 270.7 & 491.6 & 187.3 \\
\hline \multirow[b]{2}{*}{$\mathbf{R}^{2}$} & 220.2 & 408.3 & \multirow[b]{2}{*}{0.642} & \multirow[b]{2}{*}{0.97} & \multirow[b]{2}{*}{0.505} & \multirow[b]{2}{*}{0.732} & \multirow[b]{2}{*}{0.896} \\
\hline & 0.541 & 0.362 & & & & & \\
\hline
\end{tabular}

\section{Discussion}

Since the discovery of the MERS-CoV in 2012, tremendous research has been made globally to fill in gaps in the existing knowledge and have provided detailed and advanced information about MERS-CoV (PromedMail, 2019; WHO 2019). Still, more research is needed especially in the area of vaccines and drug discovery. The treatment of various diseases by using RNA-based therapeutics has shown promising results and continuous development with improved technologies are evolving. Several studies have investigated the important role of RNAi technology in the fight against many viral diseases [41-43]. The technology provides a very specific route to silence the function of the desired gene and is being used to develop therapeutics against many diseases [29]. Earlier studies were faced by obstacles like off-target binding, delivery, and stability and stimulation of immune responses which significantly contributed to hampering the use of RNAi technology as therapeutics. But, continuous research have successfully overcome these hindrances and the technology is now in clinical trials for use as therapeutics against several infectious diseases [44-51]. The specificity and potency of predicted siRNAs can be improved using updated softwares [24,39].

Recently, multiple siRNAs against HCV 5'-NTR have been designed and tested. The results showed that HCV321, HCV353, HCV258 siRNA were the most efficient siRNAs against HCV replication [50,52]. The in silico predicted siRNAs were expected to be more efficacious to inhibit the MERS-CoV replication.

The MERS-CoV replication process initiates by the binding of the viral particle with cellular receptors through the S-protein. ORF1ab includes two-thirds of the coronaviruses genome, is responsible for encoding non-structural proteins [53]. The RNA-dependent RNA polymerase and helicase proteins that are encoded by ORF1ab are involved in the transcription and replication of the virus by forming replication-transcription complexes [54]. The replication-transcription complexes assemble at the perinuclear regions and associate with double-membrane vesicles derived from the endoplasmic reticulum [55]. ORF1ab gene was selected as a target for this study for several reasons, first it is long enough to give a chance for design and selection of multiple candidate siRNAs, second because of its role in viral transcription and replication making it a possible target to control the virus replication and last because it showed high similarities ( $>99 \%$ based on multiple sequence alignment) among MERS-CoV strains retrieved from GenBank. Earlier studies have previously reported the design of siRNAs and miRNAs against MERS-CoV-Orflab gene using bioinformatics tools [30,31] but their cytotoxicity and antiviral activities have not been evaluated. The potential of RNAi technology for the treatment of viral infections has encouraged us to investigate their potential as antiviral therapy candidates against MERS$\mathrm{CoV}$.

As a preliminary test for the proof of concept, our primary objective was to in silico predict and design a potential siRNA. Then the second objective was to evaluate the cytotoxicity study of predicted siRNAs into Vero cells. In this study, we have predicted, designed potential siRNAs targeting the MERS-CoV-Orflab gene by using automated online software by filtering and excluding the off-target effects [24,39]. Based on the 
extensive bioinformatics analysis, the outputs resulted into multiple potential siRNAs, but we selected only seven siRNAs against the conserved target MERS-CoV ORF1ab gene with improved target accessibility and high expected antiviral potency and no off-target effect. The designed siRNAs were chemically synthesized and we evaluated the cytotoxicity of seven synthetic potential siRNAs in Vero cells using Lipofectamine 2000 mediated delivery and found them to be non-toxic with a CC50>50nM.

The rationale behind in silico designing is briefly discussed. The selection of potential siRNA starts with the target sequence input that is then reverse complemented to generate antisense siRNA 1-nt shifted overlapping 21-nt siRNAs representing putative guide sequences, excluding 21-nt siRNAs containing unwanted motifs or their complements. Amongst rest, active siRNA molecules are calculated, screened and predicted based on various sets of parameters (like base-preference rules, duplex-related issues) related to the sequences and secondary structures of the guide strands and to the secondary structure of the target mRNA. Sequences with potential identity to off-targets are further excluded using BLASTn or S-W analyses. Otherwise, if few promising or nil candidates get predicted, more antisense siRNAs can be generated and selected by using the option of sequence space expansion. Space of guide RNAs can be expanded by performing A to $\mathrm{G}$ and $\mathrm{C}$ to $\mathrm{U}$ base exchanges within guide sequences, which induce wobble pairing with the target but preserve target complementarity and thus silencing activity. This escalates the complementary guide siRNAs number by more than a factor of thousand for target sequences. However, this computational method may be biased towards the inception of active guide sequences and/or structures. Based on the empirical scoring functions, the selected candidate sequences are finally ranked [56]. Thermodynamically during RNAs interaction, the total binding energy is the sum of hybridization energy and breaking energy. Binding can occur only at positions free from prior intramolecular base pairs. The base pairs within the target site must be opened and made accessible, and so the energy used is named as disruption or breaking energy [57]. After the binding site is free of any secondary structure, intermolecular helices are formed, yielding stabilizing interaction energy. siRNA design tools (namely OligoWalk, Sirna, RNAxs) perform siRNA design aided by target accessibility criteria.

\section{Conclusions}

In conclusion, the in silico predicted and designed potential siRNAs against a specific target of MERS$\mathrm{CoV}$-orflab gene can be utilized to develop oligonucleotide-based therapeutics without off-target effects, high efficiency, and improved specificity. The results generated in this study has provided preliminary information to evaluate the virus inhibitory effect of siRNAs in multiple cells culture systems against MERS-CoV. This novel technology for the prediction of potential siRNA can be utilized against viruses for new anti-viral therapeutics after cell-based validation. The recent developments with improved technology to use therapeutic miRNA and siRNA shows the most valuable and significant breakthroughs not only in therapeutic molecules development but also in intellectual property rights and therapeutic business for pharmaceuticals industries against multiple diseases.

Author Contributions: SSS, SAE designed and executed the experiments, ZM, SSS performed bioinformatics study. SSS, SAE, ZM wrote the manuscript. EIA: Contributed in designing and execution of experiments and critically reviewed the manuscript. All authors provided critical feedback and helped shape the research, analysis and manuscript.

Funding: This study was financially supported by King Abdullah City for Science and Technology (KACST), Riyadh, Saudi Arabia for providing the grant on MERS-CoV bearing project number 39-2. Authors are grateful for financial support from the KACST, Riyadh, Saudi Arabia.

Acknowledgments: Authors are grateful for financial support from the KACST, Riyadh, Saudi Arabia. The authors would also like to gratefully acknowledge the research facility provided by Special Infectious Agents Unit, King Fahd Medical Research Center (KFMRC), King Abdulaziz University, Jeddah, Saudi Arabia.

Conflicts of Interest: All authors declare no conflict of interest exist.

\section{References}

1. Zaki, A.M.; van Boheemen, S.; Bestebroer, T.M.; Osterhaus, A.D.; Fouchier, R.A. Isolation of a novel coronavirus from a man with pneumonia in Saudi Arabia. The New England journal of medicine 2012, 367, 1814-1820, doi:10.1056/NEJMoa1211721.

2. van Boheemen, S.; de Graaf, M.; Lauber, C.; Bestebroer, T.M.; Raj, V.S.; Zaki, A.M.; Osterhaus, A.D.; Haagmans, B.L.; Gorbalenya, A.E.; Snijder, E.J., et al. Genomic characterization of a newly discovered coronavirus associated with acute respiratory distress syndrome in humans. mBio 2012, 3, doi:10.1128/mBio.00473-12.

3. Memish, Z.A.; Assiri, A.; Almasri, M.; Alhakeem, R.F.; Turkestani, A.; Al Rabeeah, A.A.; Al-Tawfiq, J.A.; Alzahrani, A.; Azhar, E.; Makhdoom, H.Q., et al. Prevalence of MERS-CoV nasal carriage and 
compliance with the Saudi health recommendations among pilgrims attending the 2013 Hajj. The Journal of infectious diseases 2014, 210, 1067-1072, doi:10.1093/infdis/jiu150.

4. Memish, Z.A.; Cotten, M.; Watson, S.J.; Kellam, P.; Zumla, A.; Alhakeem, R.F.; Assiri, A.; Rabeeah, A.A.; Al-Tawfiq, J.A. Community case clusters of Middle East respiratory syndrome coronavirus in Hafr AlBatin, Kingdom of Saudi Arabia: a descriptive genomic study. International journal of infectious diseases : IJID : official publication of the International Society for Infectious Diseases 2014, 23, 63-68, doi:10.1016/j.ijid.2014.03.1372.

5. Oboho, I.K.; Tomczyk, S.M.; Al-Asmari, A.M.; Banjar, A.A.; Al-Mugti, H.; Aloraini, M.S.; Alkhaldi, K.Z.; Almohammadi, E.L.; Alraddadi, B.M.; Gerber, S.I., et al. 2014 MERS-CoV outbreak in Jeddah--a link to health care facilities. The New England journal of medicine 2015, 372, 846-854, doi:10.1056/NEJMoa1408636.

6. Lee, S.S.; Wong, N.S. Probable transmission chains of Middle East respiratory syndrome coronavirus and the multiple generations of secondary infection in South Korea. International journal of infectious diseases : IJID : official publication of the International Society for Infectious Diseases 2015, 38, 65-67, doi:10.1016/j.ijid.2015.07.014.

7. Azhar, E.I.; El-Kafrawy, S.A.; Farraj, S.A.; Hassan, A.M.; Al-Saeed, M.S.; Hashem, A.M.; Madani, T.A. Evidence for camel-to-human transmission of MERS coronavirus. The New England journal of medicine 2014, 370, 2499-2505, doi:10.1056/NEJMoa1401505.

8. Assiri, A.; Al-Tawfiq, J.A.; Al-Rabeeah, A.A.; Al-Rabiah, F.A.; Al-Hajjar, S.; Al-Barrak, A.; Flemban, H.; Al-Nassir, W.N.; Balkhy, H.H.; Al-Hakeem, R.F. Epidemiological, demographic, and clinical characteristics of 47 cases of Middle East respiratory syndrome coronavirus disease from Saudi Arabia: a descriptive study. The Lancet infectious diseases 2013, 13, 752-761.

9. Omrani, A.S.; Al-Tawfiq, J.A.; Memish, Z.A. Middle East respiratory syndrome coronavirus (MERSCoV): animal to human interaction. Pathogens and global health 2015, 109, 354-362.

10. Taxman, D.J.; Livingstone, L.R.; Zhang, J.; Conti, B.J.; Iocca, H.A.; Williams, K.L.; Lich, J.D.; Ting, J.P.; Reed, W. Criteria for effective design, construction, and gene knockdown by shRNA vectors. BMC biotechnology 2006, 6, 7, doi:10.1186/1472-6750-6-7.

11. Umbach, J.L.; Cullen, B.R. The role of RNAi and microRNAs in animal virus replication and antiviral immunity. Genes $\mathcal{E}$ development 2009, 23, 1151-1164, doi:10.1101/gad.1793309.

12. Xie, Z.H. [Advances in mechanism of small RNAs]. Yi chuan= Hereditas 2009, 31, 1205-1213.

13. Liu, C.; Liang, Z.; Kong, X. Efficacy Analysis of Combinatorial siRNAs against HIV Derived from One Double Hairpin RNA Precursor. Frontiers in microbiology 2017, 8, 1651, doi:10.3389/fmicb.2017.01651.

14. Taning, C.N.T.; Christiaens, O.; Li, X.; Swevers, L.; Casteels, H.; Maes, M.; Smagghe, G. Engineered Flock House Virus for Targeted Gene Suppression Through RNAi in Fruit Flies (Drosophila melanogaster) in Vitro and in Vivo. Frontiers in physiology 2018, 9, 805, doi:10.3389/fphys.2018.00805.

15. Bar, A.; Marchand, V.; Khoury, G.; Dreumont, N.; Mougin, A.; Robas, N.; Stevenin, J.; Visvikis, A.; Branlant, C. Structural and functional analysis of the Rous Sarcoma virus negative regulator of splicing and demonstration of its activation by the 9G8 SR protein. Nucleic acids research 2011, 39, 3388-3403, doi:10.1093/nar/gkq1114.

16. Idrees, S.; Ashfaq, U.A. RNAi: antiviral therapy against dengue virus. Asian Pacific journal of tropical biomedicine 2013, 3, 232-236, doi:10.1016/s2221-1691(13)60057-x.

17. Shahid, I.; AlMalki, W.H.; AlRabia, M.W.; Mukhtar, M.H.; Almalki, S.S.R.; Alkahtani, S.A.; Ashgar, S.S.; Faidah, H.S.; Hafeez, M.H. In vitro inhibitory analysis of consensus siRNAs against NS3 gene of hepatitis C virus 1a genotype. Asian Pacific journal of tropical medicine 2017, 10, 701-709, doi:10.1016/j.apjtm.2017.07.011.

18. Tsai, K.; Courtney, D.G.; Kennedy, E.M.; Cullen, B.R. Influenza A virus-derived siRNAs increase in the absence of NS1 yet fail to inhibit virus replication. RNA (New York, N.Y.) 2018, 24, 1172-1182, doi:10.1261/rna.066332.118.

19. Huang, D.T.; Lu, C.Y.; Shao, P.L.; Chang, L.Y.; Wang, J.Y.; Chang, Y.H.; Lai, M.J.; Chi, Y.H.; Huang, L.M. In vivo inhibition of influenza A virus replication by RNA interference targeting the PB2 subunit via intratracheal delivery. PloS one 2017, 12, e0174523, doi:10.1371/journal.pone.0174523.

20. Hamasaki, K.; Nakao, K.; Matsumoto, K.; Ichikawa, T.; Ishikawa, H.; Eguchi, K. Short interfering RNAdirected inhibition of hepatitis B virus replication. FEBS letters 2003, 543, 51-54.

21. Wang, Y.J.; Yang, L.; Zuo, J.P. Recent developments in antivirals against hepatitis B virus. Virus research 2016, 213, 205-213, doi:10.1016/j.virusres.2015.12.014.

22. Zeng, J.; Yang, S.; Wang, X.; Gao, Y.; Zhang, M. Effects of siRNA-mediated suppression of HPV-11 L1 expression on the proliferation and apoptosis of vaginal epithelial cells. Experimental and therapeutic medicine 2017, 13, 1561-1565, doi:10.3892/etm.2017.4120. 
23. Kumar, V.; Jung, Y.S.; Liang, P.H. Anti-SARS coronavirus agents: a patent review (2008 - present). Expert opinion on therapeutic patents 2013, 23, 1337-1348, doi:10.1517/13543776.2013.823159.

24. Mysara, M.; Garibaldi, J.M.; Elhefnawi, M. MysiRNA-designer: a workflow for efficient siRNA design. PloS one 2011, 6, e25642, doi:10.1371/journal.pone.0025642.

25. Fakhr, E.; Zare, F.; Teimoori-Toolabi, L. Precise and efficient siRNA design: a key point in competent gene silencing. Cancer gene therapy 2016, 23, 73-82, doi:10.1038/cgt.2016.4.

26. Sohrab, S.S.; El-Kafrawy, S.A.; Mirza, Z.; Kamal, M.A.; Azhar, E.I. Design and Delivery of Therapeutic siRNAs: Application to MERS-Coronavirus. Current pharmaceutical design 2018, 24, 62-77, doi:10.2174/1381612823666171109112307.

27. Wang, Z.; Ren, L.; Zhao, X.; Hung, T.; Meng, A.; Wang, J.; Chen, Y.G. Inhibition of severe acute respiratory syndrome virus replication by small interfering RNAs in mammalian cells. Journal of virology 2004, 78, 7523-7527, doi:10.1128/jvi.78.14.7523-7527.2004.

28. Zheng, B.J.; Guan, Y.; Hez, M.L.; Sun, H.; Du, L.; Zheng, Y.; Wong, K.L.; Chen, H.; Chen, Y.; Lu, L., et al. Synthetic peptides outside the spike protein heptad repeat regions as potent inhibitors of SARSassociated coronavirus. Antiviral therapy 2005, 10, 393-403.

29. Chakraborty, C.; Sharma, A.R.; Sharma, G.; Doss, C.G.P.; Lee, S.S. Therapeutic miRNA and siRNA: Moving from Bench to Clinic as Next Generation Medicine. Molecular therapy. Nucleic acids 2017, 8, 132143, doi:10.1016/j.omtn.2017.06.005.

30. Nur, S.M.; Hasan, M.A.; Amin, M.A.; Hossain, M.; Sharmin, T. Design of Potential RNAi (miRNA and siRNA) Molecules for Middle East Respiratory Syndrome Coronavirus (MERS-CoV) Gene Silencing by Computational Method. Interdisciplinary sciences, computational life sciences 2015, 7, 257-265, doi:10.1007/s12539-015-0266-9.

31. Hasan, M.M.; Akter, R.; Ullah, M.S.; Abedin, M.J.; Ullah, G.M.; Hossain, M.Z. A Computational Approach for Predicting Role of Human MicroRNAs in MERS-CoV Genome. Advances in bioinformatics 2014, 2014, 967946, doi:10.1155/2014/967946.

32. Saebo, P.E.; Andersen, S.M.; Myrseth, J.; Laerdahl, J.K.; Rognes, T. PARALIGN: rapid and sensitive sequence similarity searches powered by parallel computing technology. Nucleic acids research 2005, 33, W535-539, doi:10.1093/nar/gki423.

33. Birmingham, A.; Anderson, E.M.; Reynolds, A.; Ilsley-Tyree, D.; Leake, D.; Fedorov, Y.; Baskerville, S.; Maksimova, E.; Robinson, K.; Karpilow, J., et al. 3' UTR seed matches, but not overall identity, are associated with RNAi off-targets. Nature methods 2006, 3, 199-204, doi:10.1038/nmeth854.

34. Pruitt, K.D.; Tatusova, T.; Maglott, D.R. NCBI reference sequences (RefSeq): a curated non-redundant sequence database of genomes, transcripts and proteins. Nucleic acids research 2007, 35, D61-65, doi:10.1093/nar/gkl842.

35. Jackson, A.L.; Burchard, J.; Leake, D.; Reynolds, A.; Schelter, J.; Guo, J.; Johnson, J.M.; Lim, L.; Karpilow, J.; Nichols, K., et al. Position-specific chemical modification of siRNAs reduces "off-target" transcript silencing. RNA (New York, N.Y.) 2006, 12, 1197-1205, doi:10.1261/rna.30706.

36. Shabalina, S.A.; Spiridonov, A.N.; Ogurtsov, A.Y. Computational models with thermodynamic and composition features improve siRNA design. BMC bioinformatics 2006, 7, 65, doi:10.1186/1471-2105-765.

37. Tafer, H.; Ameres, S.L.; Obernosterer, G.; Gebeshuber, C.A.; Schroeder, R.; Martinez, J.; Hofacker, I.L. The impact of target site accessibility on the design of effective siRNAs. Nature biotechnology 2008, 26, 578-583, doi:10.1038/nbt1404.

38. Chan, C.Y.; Carmack, C.S.; Long, D.D.; Maliyekkel, A.; Shao, Y.; Roninson, I.B.; Ding, Y. A structural interpretation of the effect of GC-content on efficiency of RNA interference. BMC bioinformatics 2009, 10 Suppl 1, S33, doi:10.1186/1471-2105-10-s1-s33.

39. Naito, Y.; Yoshimura, J.; Morishita, S.; Ui-Tei, K. siDirect 2.0: updated software for designing functional siRNA with reduced seed-dependent off-target effect. BMC bioinformatics 2009, 10, 392, doi:10.1186/1471-2105-10-392.

40. Naito, Y.; Ui-Tei, K. siRNA Design Software for a Target Gene-Specific RNA Interference. Frontiers in genetics 2012, 3, 102, doi:10.3389/fgene.2012.00102.

41. Vert, J.P.; Foveau, N.; Lajaunie, C.; Vandenbrouck, Y. An accurate and interpretable model for siRNA efficacy prediction. BMC bioinformatics 2006, 7, 520, doi:10.1186/1471-2105-7-520.

42. Jeang, K.T. RNAi in the regulation of mammalian viral infections. BMC biology 2012, 10, 58, doi:10.1186/1741-7007-10-58.

43. Houzet, L.; Jeang, K.T. MicroRNAs and human retroviruses. Biochimica et biophysica acta 2011, 1809, 686693, doi:10.1016/j.bbagrm.2011.05.009. 
44. DeVincenzo, J.; Cehelsky, J.E.; Alvarez, R.; Elbashir, S.; Harborth, J.; Toudjarska, I.; Nechev, L.; Murugaiah, V.; Van Vliet, A.; Vaishnaw, A.K. Evaluation of the safety, tolerability and pharmacokinetics of ALN-RSV01, a novel RNAi antiviral therapeutic directed against respiratory syncytial virus (RSV). Antiviral research 2008, 77, 225-231.

45. Stein, D.A.; Perry, S.T.; Buck, M.D.; Oehmen, C.S.; Fischer, M.A.; Poore, E.; Smith, J.L.; Lancaster, A.M.; Hirsch, A.J.; Slifka, M.K., et al. Inhibition of dengue virus infections in cell cultures and in AG129 mice by a small interfering RNA targeting a highly conserved sequence. Journal of virology 2011, 85, 1015410166, doi:10.1128/jvi.05298-11.

46. Kakumani, P.K.; Ponia, S.S.; S, R.K.; Sood, V.; Chinnappan, M.; Banerjea, A.C.; Medigeshi, G.R.; Malhotra, P.; Mukherjee, S.K.; Bhatnagar, R.K. Role of RNA interference (RNAi) in dengue virus replication and identification of NS4B as an RNAi suppressor. Journal of virology 2013, 87, 8870-8883, doi:10.1128/jvi.02774-12.

47. Carneiro, B.; Braga, A.C.; Batista, M.N.; Harris, M.; Rahal, P. Evaluation of canonical siRNA and Dicer substrate RNA for inhibition of hepatitis $\mathrm{C}$ virus genome replication--a comparative study. PloS one 2015, 10, e0117742, doi:10.1371/journal.pone.0117742.

48. Moon, J.S.; Lee, S.H.; Kim, E.J.; Cho, H.; Lee, W.; Kim, G.W.; Park, H.J.; Cho, S.W.; Lee, C.; Oh, J.W. Inhibition of Hepatitis C Virus in Mice by a Small Interfering RNA Targeting a Highly Conserved Sequence in Viral IRES Pseudoknot. PloS one 2016, 11, e0146710, doi:10.1371/journal.pone.0146710.

49. Mandal, A.; Ganta, K.K.; Chaubey, B. Combinations of siRNAs against La Autoantigen with NS5B or hVAP-A Have Additive Effect on Inhibition of HCV Replication. Hepatitis research and treatment 2016, 2016, 9671031, doi:10.1155/2016/9671031.

50. ElHefnawi, M.; Kim, T.; Kamar, M.A.; Min, S.; Hassan, N.M.; El-Ahwany, E.; Kim, H.; Zada, S.; Amer, M.; Windisch, M.P. In Silico Design and Experimental Validation of siRNAs Targeting Conserved Regions of Multiple Hepatitis C Virus Genotypes. PloS one 2016, 11, e0159211, doi:10.1371/journal.pone.0159211.

51. Braga, A.C.; Carneiro, B.M.; Batista, M.N.; Akinaga, M.M.; Rahal, P. Inhibition of hepatitis C virus using siRNA targeted to the virus and Hsp90. Cell stress $\mathcal{E}$ chaperones 2017, 22, 113-122, doi:10.1007/s12192016-0747-8.

52. Chandra, P.K.; Kundu, A.K.; Hazari, S.; Chandra, S.; Bao, L.; Ooms, T.; Morris, G.F.; Wu, T.; Mandal, T.K.; Dash, S. Inhibition of hepatitis C virus replication by intracellular delivery of multiple siRNAs by nanosomes. Molecular therapy : the journal of the American Society of Gene Therapy 2012, 20, 1724-1736, doi:10.1038/mt.2012.107.

53. Perlman, S.; Netland, J. Coronaviruses post-SARS: update on replication and pathogenesis. Nature reviews. Microbiology 2009, 7, 439-450, doi:10.1038/nrmicro2147.

54. Sawicki, S.G.; Sawicki, D.L.; Siddell, S.G. A contemporary view of coronavirus transcription. Journal of virology 2007, 81, 20-29, doi:10.1128/jvi.01358-06.

55. Zumla, A.; Hui, D.S.; Perlman, S. Middle East respiratory syndrome. Lancet (London, England) 2015, 386, 995-1007, doi:10.1016/s0140-6736(15)60454-8.

56. Patzel, V. In silico selection of active siRNA. Drug discovery today 2007, 12, 139-148, doi:10.1016/j.drudis.2006.11.015.

57. Tafer, H. Bioinformatics of siRNA design. In RNA Sequence, Structure, and Function: Computational and Bioinformatic Methods, Springer: 2014; pp. 477-490. 